\title{
Al-doping and Properties of AZO Thin Films Grown at Room Temperature: Sputtering Pressure Effect
}

\author{
Michel Chaves ${ }^{a}$, Raul Ramos ${ }^{a}$, Everson Martins ${ }^{a}$, Elidiane Cipriano Rangel ${ }^{a} \bowtie$, \\ Nilson Cristino da Cruz ${ }^{a}$, Steven Frederick Durrant ${ }^{\circledR}$, José Roberto Ribeiro Bortoleto ${ }^{a} *^{(\mathbb{C}}$ \\ ${ }^{a}$ Instituto de Ciência e Tecnologia de Sorocaba, Universidade Estadual Paulista - UNESP, Avenida Três \\ de Março 511, 18087-180, Sorocaba, SP, Brasil
}

Received: October 09, 2018; Revised: December 19, 2018; Accepted: January 23, 2019

\begin{abstract}
Aluminum zinc oxide (AZO) thin films were synthesized on glass substrates by radio frequency (rf) magnetron sputtering from a metallic $\mathrm{Zn}-\mathrm{Al}$ (5 at. \%) target at room temperature. The morphological, structural, electrical and optical properties of the films were studied as a function of the sputtering pressure, which was varied from 0.1 to $6.7 \mathrm{~Pa}$. X-ray diffraction (XRD) analyses revealed that the films obtained were polycrystalline, having a hexagonal wurtzite structure with a preferential orientation in the (002) plane. In addition, the crystallite size increased as a function of sputtering pressure. Owing to the re-sputtering of the $\mathrm{Zn}$ atoms from the growing film, the aluminum concentration presented a maximum value of 13 at. \%. At pressures close to $0.16 \mathrm{~Pa}$, we obtained films with values of electrical resistivity and mobility of $2.810^{-3} \Omega \mathrm{cm}$ and $17 \mathrm{~cm}^{2} / \mathrm{Vs}$, respectively. Finally, our results indicate that the structure zone diagram proposed by Thornton and later modified by Kluth does not fully predict the structural/morphological behavior of the AZO films, since plasma interactions must also be taken into account. With the methodology used, transparent conductive electrodes can be deposited on substrates at low temperatures.
\end{abstract}

Keywords: $\mathrm{ZnO}$ :Al thin films, TCO, morphological properties, structure zone diagram, room temperature.

\section{Introduction}

Transparent conductive oxides (TCO) are materials based on metallic oxides capable of conducting electric current without deterioration in their optical transmission ${ }^{1}$, exhibiting a resistivity of roughly $10^{-3}$ to $10^{-4} \Omega \mathrm{cm}$ and a transmittance of about $80 \%$ in the visible region ${ }^{2}$. These films find diverse applications in optoelectronic devices, such as liquid crystal displays, touch-sensitive panels, flat-screen monitors, infrared optical windows and photovoltaic cells $\mathrm{s}^{3-5}$. Several materials are used for the production of TCO films, indium oxide doped with tin, known as ITO $\left(\operatorname{In}_{2} \mathrm{O}_{3}: \mathrm{Sn}\right)$, is the most popular ${ }^{2,4}$. The rising demand for optoelectronic devices, however, has accelerated the depletion of reserves of indium, the main component of ITO and, consequently, increased its fabrication $\cos ^{3-5}$. Furthermore, as pointed by Minami et al. ${ }^{4}$, applications in flat display panels (FDPs) technology involves the growth process of TCO thin films (thickness below $200 \mathrm{~nm}$ ) at temperatures below approximately $200^{\circ} \mathrm{C}$.

In this context, many investigations have sought alternatives to $\mathrm{ITO}^{5}$. Owing to its characteristics such as low toxicity, low production cost and stability in plasma processes $^{5}, \mathrm{AZO}$ (Aluminium doped zinc oxide, $\mathrm{ZnO}: \mathrm{Al}$ ) is a strong candidate to substitute ITO. The substitution of zinc by aluminum in the $\mathrm{ZnO}$ matrix should increase the carrier concentration, leading to a reduction in resistivity. In addition, AZO may be synthesized by techniques such as MOCVD', atomic layer deposition ${ }^{7}$, laser ablation ${ }^{8}$, electrochemical deposition ${ }^{9}$ and sputtering ${ }^{10-15}$. The last of these permits the synthesis of AZO thin films at low temperatures ${ }^{12-14}$ and over flexible substrates ${ }^{15}$.

The structural, electrical and optical properties of AZO films grown by magnetron sputtering have been investigated extensively as function of the deposition parameters, such as plasma source $^{3-12}$, temperature ${ }^{16,17}$, sputtering pressure ${ }^{18-20}$ and doping level ${ }^{21,22}$. There are reports in the literature, however, that show distinct dependencies of the film properties on a single growth parameter. For example, Kluth et al. ${ }^{23}$ reported that the electrical resistivity increases as the pressure is increased from 0.04 to $2.70 \mathrm{~Pa}$. On the other hand, Czternastek ${ }^{18}$ reported that the electrical resistivity decreased with pressure in the range of 6 to $10 \mathrm{~Pa}$. These results indicate that the effect of sputtering pressure on the film properties depends on the other deposition parameters, such as the substrate temperature and the plasma configuration. The present study reports the influence of sputtering pressure on the morphological, structural, optical and electrical properties when AZO films (thickness about $200 \mathrm{~nm}$ ) are synthesized by RF magnetron sputtering at room temperature. 


\section{Experimental Details}

The AZO films were grown on $25 \times 20 \mathrm{~mm}^{2}$ glass substrates of $1 \mathrm{~mm}$ thickness by reactive RF magnetron sputtering at room temperature, varying the sputtering pressure from 0.1 to $6.7 \mathrm{~Pa}$ in a mixture of $\mathrm{Ar}+\mathrm{O}_{2}$ gases, where the oxygen partial pressure was maintained at about $0.015 \mathrm{~Pa}$. Before deposition the substrates were ultra-sonically cleaned in distilled water with detergent, isopropyl alcohol, and subsequently dried in an air stream. The deposition system consists of a stainless-steel chamber of $270 \mathrm{~mm}$ diameter and $200 \mathrm{~mm}$ in height. A 3 in. metallic Zn-Al (5 at. \%) target was used to optimize the doping effects ${ }^{24}$. To maximize the plasma effects ${ }^{12}$, a substrate to target-holder distance of $20 \mathrm{~mm}$ was used. The chamber was evacuated using a turbo molecular pump (Edwards T-Station 75) and the pressure was monitored using Pirani (KJL 945) and Baratron gauges. To control the gases needle valves (Edwards, model LV-10K) and a mass flow controller (MKS 1179A) were used. The plasma was activated by a radiofrequency (RF) source $(13.56 \mathrm{MHz}, 300$ $\mathrm{W})$ connected to the target holder. A fixed deposition time of $20 \mathrm{~min}$ was used at a power of $70 \mathrm{~W}$.

The composition and $\mathrm{Al}$ content $([\mathrm{Al}] /([\mathrm{Zn}]+[\mathrm{Al}])$ atomic ratio) of the $\mathrm{Zn}-\mathrm{Al}$ target and the $\mathrm{AZO}$ films were measured by Energy-dispersive X-ray spectroscopy (EDS). For this, an EDS coupled to the scanning electron microscope (Jeol JSM-6010) was used. The surface morphology was investigated using Atomic Force Microscopy (AFM) with a XE-100 Park Systems in non-contact mode over a scan area of $2 \mu m \times 2 \mu m$.

The crystalline structure of the AZO films was studied using X-ray Diffraction (XRD) in $\theta-2 \theta$ mode as well as at a grazing incidence angle of $2^{\circ}$, using a diffractometer (Panalytical X' Pert Powder) with the $\mathrm{CuK}_{\alpha}$ radiation at a wavelength of $1.5405 \AA$. The average crystallite size $\tau$, was estimated using Scherrer's equation (1), where $k$ is the shape factor (usually 0.9 ), $\lambda$ is the $X$-ray wavelength, $\beta$ is the FWHM and $\theta$ is the Bragg diffraction angle of the (002) peak in the $\theta-2 \theta$ mode.

$$
\tau=\frac{k \lambda}{\beta \cos \theta}
$$

Film thickness was measured using a perfilometer (Veeco Instruments, Dektak 150) and electrical resistivity measurements were made using the four-point probe linear method $^{25,26}$. Optical reflection and transmission spectra were obtained using a Uv-Vis-NIR spectrometer (Perkin Elmer, Lambda 750) in the wavelength range of 190 to $3300 \mathrm{~nm}$. The optical gaps were estimated by equation $(2)^{14}$ :

$$
\alpha h v=B\left(h v-E_{g}\right)^{1 / 2}
$$

where $\alpha$ is the absorption coefficient, $h v$ is the incident photon energy, $E_{g}$ is the optical gap energy for direct allowed transitions and $\mathrm{B}$ is a constant dependent on the refractive index of the material, the electron effective mass and the speed of light in vacuum. Plotting $(\alpha h v)^{2}$ as a function of the incident energy $(h v)$ the optical gap may be estimated by extrapolating the linear portion of the line until it intercepts the x-axis, at which point $\alpha h v=0$.

\section{Results and Discussions}

\subsection{Surface morphology}

Figure 1 shows AFM surface images of the AZO thin films deposited at different sputtering pressures. The surface morphology is mainly characterized by small granular structures. As the pressure increases, however, surface structures of greater lateral size and height appear and the surface becomes rougher.

Table 1 shows the thickness, growth rate, RMS roughness and RMS/thickness ratio for different sputtering pressures. The RMS roughness of AZO thin films was calculated from the AFM images shown in Figure 1.

The growth rate remained between 8.8 and $13 \mathrm{~nm} / \mathrm{min}$. For easier visualization, we plot the growth rate as a function of the sputtering pressure in Figure 2. The growth rate reaches a maximum at around $2 \mathrm{~Pa}$. For lower pressures, the sputtering rate of $\mathrm{Zn}$ atoms from the target is limited by the low density of $\mathrm{Ar}^{+}$ions in the plasma. When the pressure is increased, the sputtering of $\mathrm{Zn}$ becomes more effective. At higher pressures, however, the scattering coefficient increases due to collisions in the plasma and, consequently, the number of sputtered $\mathrm{Zn}$ atoms reaching the substrate decreases again. In fact, according to equation (3) the mean free path, $\lambda$, is given $b y^{27}$ :

$$
\lambda=\frac{6.7}{P}
$$

where $\lambda$ is expressed in $\mathrm{mm}$ e $\mathrm{P}$ is the pressure in $\mathrm{Pa}$. Then for a pressure of $2 \mathrm{~Pa}$ the mean free path is $\lambda \sim 3.4 \mathrm{~mm}$. Since the target-substrate distance is $20 \mathrm{~mm}$, sputtered atoms and ions suffer multiple collisions with the process gas particles before reaching the film surface. Furthermore, the plasma density over the growing surface increases at higher pressures. This effect is considerable when the unbalanced configuration is used or when, as in our case, the target is very close to the substrate. Consequently, desorption of $\mathrm{Zn}$ adatoms is enhanced and the growth rate is further reduced.

The RMS roughness presents a maximum value around $10.2 \mathrm{~nm}$ at 5.3 Pa, as shown in Table 1. We should remember, however, that the surface roughness also evolves with film thickness ${ }^{28}$. Thus we have analyzed the behavior of the roughness/thickness ratio instead of the RMS roughness, as shown in Figure 2. One can observe that the RMS/thickness increases continuously up to $4 \mathrm{~Pa}$ and thereafter it stabilizes around the value of 0.05 . The rise in the RMS roughness/ 


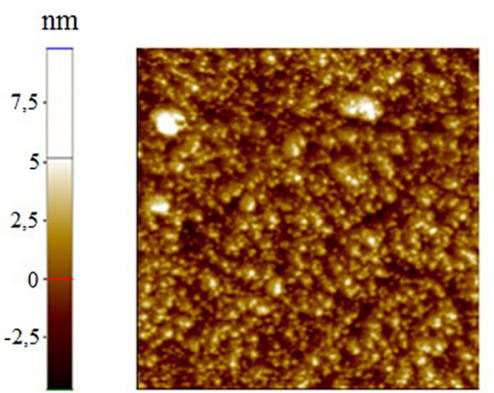

(a)

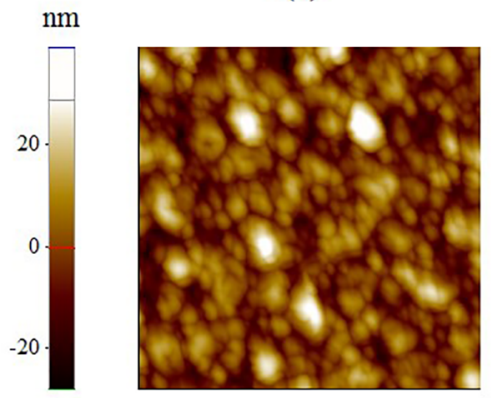

(d)

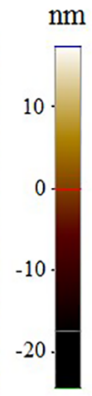

$\mathrm{nm}$

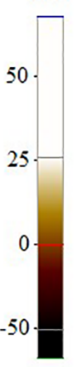

(b)

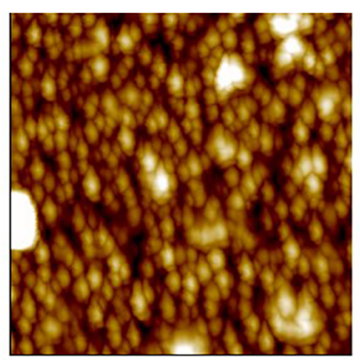

(e)

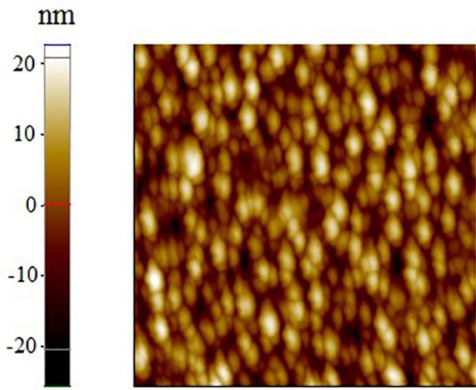

(c)
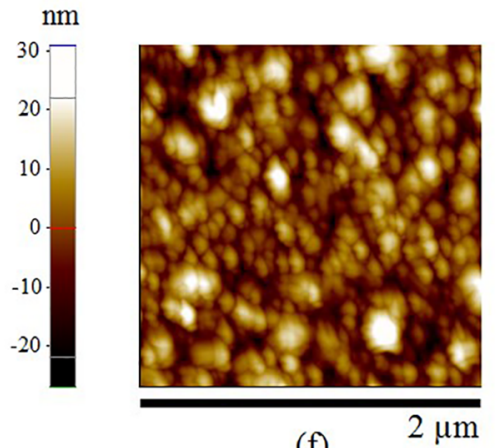

(f)

Figure 1. $2 \mu \mathrm{m}$ x $2 \mu \mathrm{m}$ AFM images of AZO films produced at different sputtering pressures: (a) $0.16 \mathrm{~Pa}$, (b) $1.3 \mathrm{~Pa}$, (c) $2.7 \mathrm{~Pa}$, (d) 4.0 $\mathrm{Pa}$ (e) 5.3 Pa and (f) 6.7 Pa.

Table 1. Thickness, growth rate, RMS roughness and roughness/thickness ratio for AZO thin films. The RMS roughness of glass is about $0.3 \mathrm{~nm}$.

\begin{tabular}{lcccccc}
\hline Pressure (Pa) & $\mathbf{0 . 1 6}$ & $\mathbf{1 . 3}$ & $\mathbf{2 . 7}$ & $\mathbf{4 . 0}$ & $\mathbf{5 . 3}$ & $\mathbf{6 . 7}$ \\
\hline Thickness (nm) & $130 \pm 10$ & $260 \pm 20$ & $260 \pm 20$ & $200 \pm 15$ & $210 \pm 50$ & $170 \pm 20$ \\
Growth rate (nm/min) & $8.8 \pm 0.7$ & $13 \pm 1$ & $13 \pm 1$ & $10 \pm 1$ & $10 \pm 3$ & $8 \pm 1$ \\
$\mathbf{R}_{\text {rms }}$ (nm) & 1.5 & 5.5 & 7.9 & 9.2 & 10.2 & 8.4 \\
$\mathbf{R}_{\text {rms }} /$ Thickness & $0.011 \pm 0.001$ & $0.021 \pm 0.001$ & $0.030 \pm 0.004$ & $0.046 \pm 0.005$ & $0.050 \pm 0.010$ & $0.050 \pm 0.006$ \\
\hline
\end{tabular}

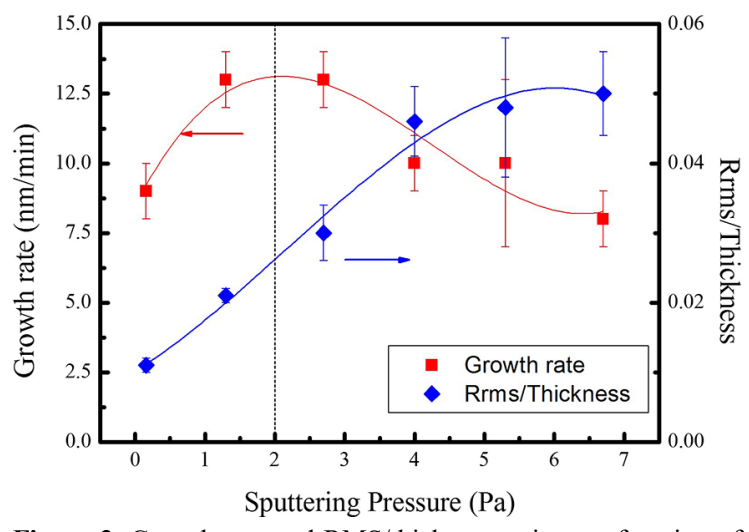

Figure 2. Growth rate and RMS/thickness ratio as a function of the sputtering pressure for AZO films.

thickness ratio simultaneously with the formation of 3D structures is consistent with a rougher texture caused by an increase of the crystallite size as indicated by the XRD measurements.

\subsection{Composition and structural properties}

Table 2 presents the ratio of concentrations of oxygen and of aluminum to the total metal content calculated from the EDS data. The $[\mathrm{O}] /([\mathrm{Zn}]+[\mathrm{Al}])$ ratio is around 0.85 for all sputtering pressures. This indicates that all samples were grown under sub-stoichiometric conditions, i.e., metallic mode growth. The $[\mathrm{Al}] /([\mathrm{Zn}]+[\mathrm{Al}])$ ratio increases from 0.06 up to 0.13 when sputtering pressure is increased to $1.3 \mathrm{~Pa}$. For all samples, the aluminum concentration is greater than that found in the target used as the precursor (5 at.\%). This result can be attributed to the bombardment of the growing film surface by plasma species, mainly by oxygen ions $\left(\mathrm{O}^{-}\right)$. As discussed before, the plasma plume promotes the bombardment and intensifies the re-sputtering rate of $\mathrm{Zn}$ adatoms, producing an increase in the concentration of $\mathrm{Al}$ in the film since the binding energy of Al-O is higher than that of $\mathrm{Zn}-\mathrm{O}$. This excess of $\mathrm{Al}$ concentration in the film was also reported by Cornelius et. $\mathrm{al}^{21}$. In this case, the $\mathrm{Zn}$ desorption and, consequently, the higher Al-concentration, 
Table 2. The Oxygen and $\mathrm{Al}$ ratios deduced from the elemental composition obtained by EDS measurements. [Al]/([Zn]+[Al]) ratio in the metallic target is $0.05 . \mathrm{N}_{\mathrm{Al}}$ represents the density of $\mathrm{Al}$ atoms in the films.

\begin{tabular}{ccccccc}
\hline Pressure (Pa) & $\mathbf{0 . 1 6}$ & $\mathbf{1 . 3}$ & $\mathbf{2 . 7}$ & $\mathbf{4 . 0}$ & $\mathbf{5 . 3}$ & $\mathbf{6 . 7}$ \\
\hline$\frac{[O]}{[Z n]+[A l]}$ & 0.86 & 0.87 & 0.79 & 0.92 & 0.86 & 0.81 \\
$\frac{[A l]}{[Z n]+[A l]}$ & 0.06 & 0.13 & 0.12 & 0.13 & 0.83 & 0.10 \\
$\mathbf{N}_{\mathbf{A l}}\left(\mathbf{1 0}^{\mathbf{2 1}} \mathbf{c m}^{-3}\right)$ & 2.49 & 5.39 & 4.98 & 5.39 & 3.44 & 4.15 \\
\hline
\end{tabular}

is stressed mainly by the substrate temperature instead of plasma interactions.

Figure 3 shows the results of the grazing incidence XRD measurements. All the spectra exhibit the peaks characteristic of wurtzite ${ }^{17}$. Specifically, it is possible to observe peaks associated with the (002), (100), (101), (102), (110) and (103) planes, the (002) peak being the most intense (JCPDS 36-1451). This indicates that the crystal grows preferentially along the c-axis. The ratio of the intensities of the peaks associated with the (101) and (002) planes is also given in Table 3, and it increases from 0.05 to 0.22 as the pressure increases from 1.3 to $5.3 \mathrm{~Pa}$, falling slightly thereafter. A small (101) peak was observed at $0.16 \mathrm{~Pa}$. However, if we compare the values with the $\mathrm{ZnO}$ polycrystalline powder, we can conclude that the (002) growth alignment is changed slightly with sputtering pressure.

According to the Structure Zone Diagram (SZD) model proposed by Kluth et al. ${ }^{23}$, alignment of the $\mathrm{ZnO}$ crystallites should be increased with sputtering pressure. However, this SZD does not explicitly include plasma and ion effects on the growing film. At low pressures, sputtered species are more energetic, and may bombard the growing film surface, causing defects in the lattice and limiting the columnar growth. In particular, a fine-grained, nanocrystalline with preferred orientation is expected according to the SZD proposed by A. Anders ${ }^{29}$. On the other hand, operating at higher pressures the distribution function is shifted to lower energies. Moreover, the shadowing mechanism ${ }^{30}$, that favors rougher surfaces but not larger structures, is less effective at higher pressures, since sputtered atoms and ions are likely to experience more collisions before arriving at the growing surface. Consequently, the growth of slightly misaligned tapered crystallites takes place, as indicated by the $\mathrm{I}_{101} / \mathrm{I}_{002}$ values.

Table 3 also displays the lattice constant estimated from the $\theta-2 \theta$ XRD measurements. The constant $c$ data of the AZO films exhibit a tendency to decrease as the sputtering pressure increases. This reduction could be due to a reduction in the energy of the particles (ions and atoms) that reach the film surface. Indeed, studies by Kappertz et $a l^{31}$ revealed that $\mathrm{O}^{-}$ions may have kinetic energies, great enough to produce implantation in the growing film. This mechanism can generate dislocations and increases the lattice constant- $c$

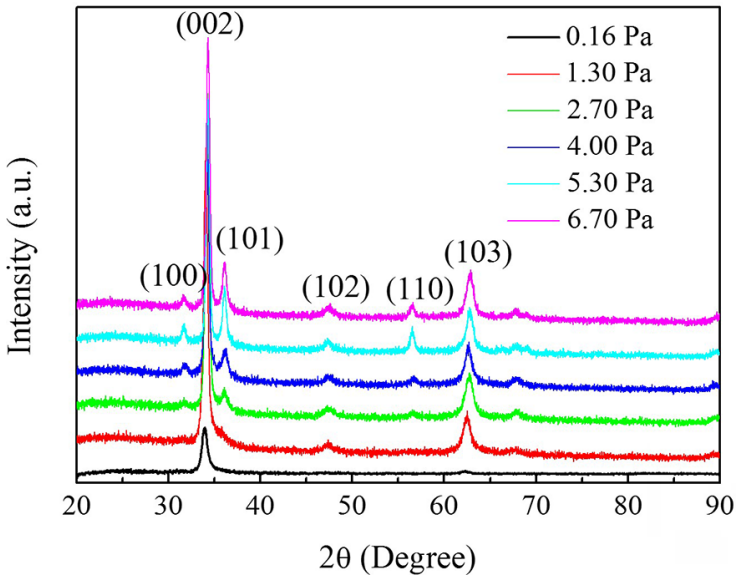

Figure 3. Grazing incidence X-ray diffraction spectra of the AZO films at different sputtering pressures.

of the AZO films. On the other hand, an increase in pressure can produce a greater number of collisions in the plasma, reducing the kinetic energy of these incoming particles. Thus, the reduction in the constant- $c$ observed at higher pressure may be caused by a reduction in the efficiency of $\mathrm{O}^{-}$ion implantation.

Figure 4 shows the crystallite size as a function of the sputtering pressure. For comparison, we include several data published in the literature ${ }^{10,14,20,32}$. For reactive series, the crystallite size increased continuously from 8.2 to $17.3 \mathrm{~nm}$ for sputtering pressures ranging from 0.16 to $6.7 \mathrm{~Pa}$. Similarly, for AZO films grown from a ceramic target the crystallite size increased from 8.7 to $17.7 \mathrm{~nm}$ for pressures ranging from 0.1 to $0.4 \mathrm{~Pa}$. Moreover, $\mathrm{Kim} \& \mathrm{Kim}^{14}$ reported crystallite sizes from 25.2 to $28.7 \mathrm{~nm}$ for pressures of 0.13 to $0.27 \mathrm{~Pa}$. For the data of G-Berasategui et al ${ }^{10}$, Zhou et al. ${ }^{32}$ and Yue et $a l .{ }^{20}$ grown at temperatures greater than $523 \mathrm{~K}$, the crystallite size is usually larger, between 30 to $70 \mathrm{~nm}$.

Two aspects are worth emphasizing: (i) crystallite size increases with temperature. This is mainly due to activation of the surface diffusion mechanism expected at higher temperatures. (ii) The crystallites increase slightly in size as a function of pressure when films are grown at room temperature. However, the inclination is reversed at higher temperatures. These points also are in agreement with the SZD proposed by A. Anders ${ }^{29}$, where columnar grains take 
Table 3. Structural results obtained by XRD analysis of the AZO films at different sputtering pressures. The bulk value is tabulated by JCPDS 36-1451 (International Centre for Diffraction Data, 1990) for the hexagonal structure ZnO.

\begin{tabular}{lcccccccc}
\hline Pressure (Pa) & $\mathbf{0 . 1 6}$ & $\mathbf{1 . 3}$ & $\mathbf{2 . 7}$ & $\mathbf{4 . 0}$ & $\mathbf{5 . 3}$ & $\mathbf{6 . 7}$ & Bulk \\
\hline $\mathbf{I}_{(\mathbf{1 0 1})} / \mathbf{I}_{(\mathbf{0 0 2})}$ ratio & - & 0.05 & 0.12 & 0.13 & 0.22 & 0.14 & 2.27 \\
$\boldsymbol{2 \theta}$ (degree) peak (002) $\pm \mathbf{0 . 0 0 0 2}$ & 34.037 & 34.033 & 34.182 & 34.190 & 34.219 & 34.334 & 34.420 \\
FWHM (degree) peak (002) & 1.012 & 0.591 & 0.595 & 0.517 & 0.507 & 0.479 & - \\
Constant-c $(\mathbf{n m}) \pm \mathbf{0 . 0 0 0 1}$ & 0.5263 & 0.5264 & 0.5242 & 0.5240 & 0.5236 & 0.5219 & 0.5207 \\
Crystallite size $(\mathbf{n m}) \pm \mathbf{0 . 1}$ & 8.2 & 14.0 & 14.0 & 16.1 & 16.4 & 17.3 & - \\
\hline
\end{tabular}

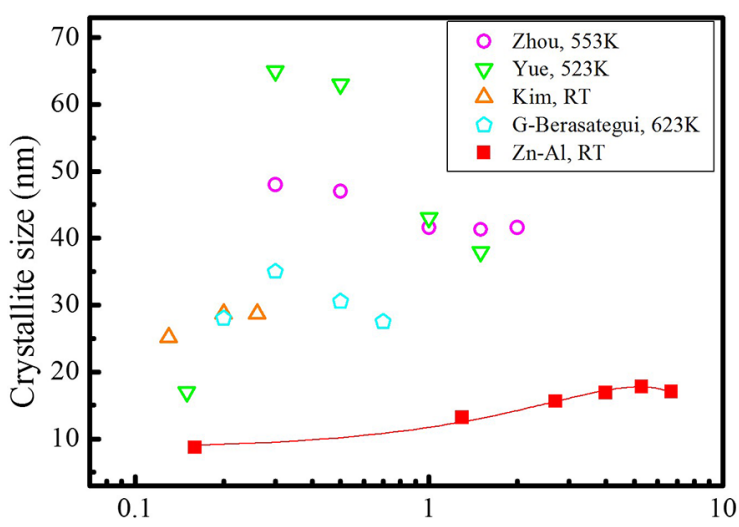

Sputtering Pressure (Pa)

Figure 4. Crystallite size of the AZO films as a function of the sputtering pressure. For comparison, crystallite sizes obtained by Zhou et al. ${ }^{32}$, Yue et al. ${ }^{20}$, Kim \& $\mathrm{Kim}^{14}$ and G-Berasategui ${ }^{10}$ are also shown.

place at higher temperatures but tapered crystallites should be predominant at lower temperatures when the sputtering pressure is raised.

\subsection{Optical and electrical properties}

All films exhibit transmittances above $80 \%$ in the visible region of the light spectrum. This implies that the variation in the sputtering pressure did not change the film transparency. Figure 5 presents square of the absorption coefficient for the AZO films deposited at different pressures. The optical gap presented values of 3.44 to $3.58 \mathrm{eV}$. For comparison, the optical gap energy of the intrinsic $\mathrm{ZnO}$ thin film grown at room temperature was $3.28 \mathrm{eV}^{30}$. This shift in the energy of the optical gap to greater values is attributed to the BursteinMoss effect expressed by Equation (4) ${ }^{33}$ :

$$
\Delta E_{n}=\left(\frac{h^{2}}{8 m^{*}}\right)\left(\frac{3}{\pi}\right)^{2 / 3} n^{2 / 3}
$$

where $m *$ is the effective mass of the electron, which for $\mathrm{ZnO}$ is equal to $0.38 m_{0}^{33}, h$ is Planck's constant and $N$ represents the carrier density. We have applied formula (4) to estimate the free electron density in the conduction band.

With the measurements of electrical resistivity obtained using the four-point probe method and the carrier density obtained using the Burstein-Moss equation, electrical mobilities were obtained by employing the relation $\rho=(\text { ne } \mu)^{-1}$.

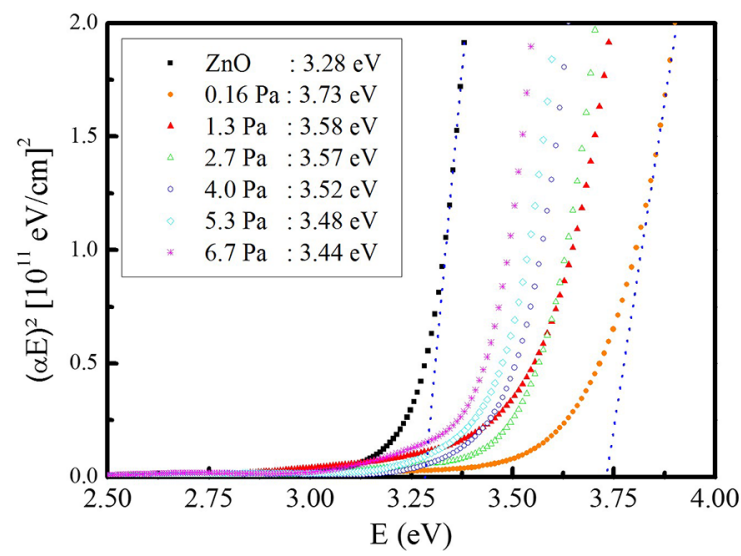

Figure 5. Square of the absorption coefficient as function of photon energy for AZO thin films grown at different sputtering pressures.

The electrical resistivity, carrier density, electrical mobility and Al-doping efficiency are shown in Table 4. Our best electrical resistivity values were obtained for the film synthesized at $0.16 \mathrm{~Pa}$, namely $2.810^{-3} \Omega \mathrm{cm}$. In this case, carrier density, electrical mobility and Al-doping efficiency were $1.310^{20} \mathrm{~cm}^{-3}, 17 \mathrm{~cm}^{2} / \mathrm{Vs}$ and $5.2 \%$, respectively. This low value of carrier density can be related to the high oxidation rate of $\mathrm{Al}$ present in the alloy during the process, producing neutral $\mathrm{Al}$ defects, for example, the $\mathrm{Al}_{2} \mathrm{O}_{3}(\mathrm{ZnO})_{\mathrm{m}}$ homologous phase $\mathrm{e}^{21,34,35}$. Furthermore, Al-doping efficiency is further reduced at higher sputtering pressure, indicating that homologous phase formation is favored. Increasing the pressure in the deposition chamber, the lifetime of $\mathrm{O}$ species is increased ${ }^{36}$, favoring reactions with the $\mathrm{Zn}$ and $\mathrm{Al}$. This can decrease the ionization efficiency of Al doping, favoring the formation of homologous phases.

Figure 6 compares our electrical resistivity data with those reported by Czternastek ${ }^{18}$ and Kluth et al. ${ }^{19}$. Kluth et al. reported the electrical resistivity for a wide range of experimental conditions. Particularly, we compare with the data for samples grown using a metallic $\mathrm{ZnAl}$ target at substrate temperature of $543 \mathrm{~K}$ and sputtering pressure ranging from 0.05 to $2 \mathrm{~Pa}$. In a Czternastek's ${ }^{18}$ work, the total pressure was varied from 2 to $14 \mathrm{~Pa}$ for distinct $\mathrm{Al}$ doping levels and the substrate temperature was kept at $470 \mathrm{~K}$. Specifically, we compare only with the data for $\mathrm{ZnO}: \mathrm{Al}$ (3 at.\%) films.

The electrical resistivity observed for Kluth ${ }^{19}$ is around one order of magnitude less than that observed here. This 
Table 4. Experimental and calculated values of the electrical properties of the AZO films synthesized from metallic $\mathrm{Zn}-\mathrm{Al}$ (5 at.\%) target.

\begin{tabular}{|c|c|c|c|c|c|c|}
\hline Pressure (Pa) & 0.16 & 1.3 & 2.7 & 4.0 & 5.3 & 6.7 \\
\hline Electrical resistivity $\left(10^{-3} \Omega \mathrm{cm}\right)$ & $2.8 \pm 0.3$ & $7.8 \pm 0.8$ & $37 \pm 4$ & 48 & 51 & $43 \pm 4$ \\
\hline Carrier density $\left(10^{20} \mathrm{~cm}^{-3}\right)$ & 1.3 & 1.7 & 1.6 & 1.2 & 1.0 & 0.7 \\
\hline Electrical mobility $\left(\mathrm{cm}^{2} / \mathrm{V} \mathrm{s}\right)$ & $17 \pm 2$ & $5 \pm 1$ & 1 & 1 & 1 & 2 \\
\hline$\% \eta\left(\mathrm{n} / \mathrm{N}_{\mathrm{Al}}\right)$ & 5.2 & 3.2 & 3.1 & 2.2 & 2.9 & 1.7 \\
\hline
\end{tabular}

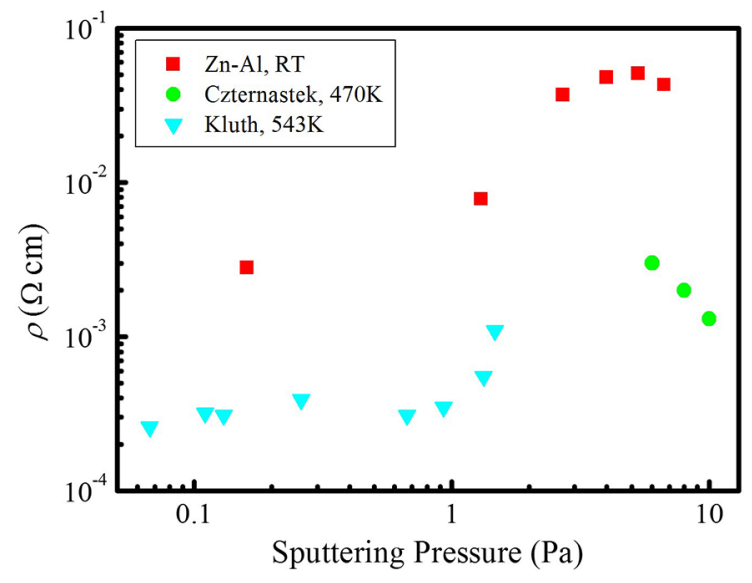

Figure 6. Electrical resistivity of $\mathrm{ZnO}$ : $\mathrm{Al}$ thin films as a function of the sputtering pressure. Literature values from Czternatek ${ }^{18}$ and Kluth et al. ${ }^{19}$ are also plotted.

difference can be attributed to the substrate temperature. According to the SZM model proposed by Anders, at higher temperature the grains are enlarged because the adatom mobility becomes the dominant growth mechanism. As a consequence, electrical mobility increases. Moreover, both data show that the electrical resistivity increases with sputtering pressure, at least up to $5 \mathrm{~Pa}$. The data of Czternastek ${ }^{18}$ show that the electrical resistivity decreases when pressure is increased from 5 to $10 \mathrm{~Pa}$. This result can be explained in the following way. In our previous work ${ }^{30}$, we observed a structural transition of $\mathrm{ZnO}$ thin films at a substrate temperature of around $473 \mathrm{~K}$ and a sputtering pressure of $1.3 \mathrm{~Pa}$. In these conditions, $\mathrm{ZnO}$ grains tend to grow more misaligned and the film density decreases According to the SZM proposed by Anders ${ }^{29}$, however, this structural transition should be shifted to higher temperatures when the sputtering pressure is increased, and columnar growth could recur. As a consequence, the electrical mobility should be enhanced. For Czternastek's ${ }^{18}$ study, when the sputtering pressure goes from 5 to $10 \mathrm{~Pa}$ at $470 \mathrm{~K}$, AZO films became more columnar and, consequently, more conductive electrically.

\section{Conclusions}

AZO films were synthesized onto glass substrates using RF magnetron sputtering at room temperature. The effects of the argon sputtering pressure in the range 0.1 to $6.7 \mathrm{~Pa}$ on the physical properties of the films were examined. All
AZO films presented a high optical transmittance (above $80 \%$ ) in the visible region. The best electrical properties were obtained at a pressure of $0.16 \mathrm{~Pa}$, yielding an electrical resistivity of $2.8 \times 10^{-3} \Omega \mathrm{cm}$. X-ray diffraction analyses of the films as a function of the sputtering pressure revealed a preferential orientation in the (002) plane. Additionally, the crystallite size tends to increase with sputtering pressure in the range of 0.1 to $6.7 \mathrm{~Pa}$. This behavior differs from the model proposed by Kluth et al. ${ }^{19}$. It can be better explained when plasma effects are taken into account in the SZD model, as proposed by A. Anders ${ }^{29}$. Finally, an increase in sputtering pressure produced a decrease in both carrier concentration and electrical mobility. As a consequence, the electrical resistivity of the films increases as a function of the sputtering pressure for films grown at room temperature. With the results obtained, transparent conductive electrodes can be produced on substrates that require low temperature deposition.

\section{Acknowledgements}

The authors thank the Brazilian agencies CAPES, FAPESP (Proc. 2008/53311-5 and 2014/21594-9) and CNPq (Proc. $555774 / 2010-4$ and 301622/2012-4) for financial support.

\section{References}

1. da Silva EP, Chaves M, Durrant SF, Lisboa-Filho PN, Bortoleto JRR. Morphological and electrical evolution of $\mathrm{ZnO}$ : Al thin films deposited by RF magnetron sputtering onto glass substrates. Materials Research. 2014;17(6):1384-1390.

2. Afre RA, Sharma N, Sharon M, Sharon M. Transparent conducting oxide films for various applications: A review. Reviews on Advanced Materials Science. 2018;53(1):79-89.

3. Szyszka B, Dewald W, Gurram SK, Andreas P, Schulz C, Siemers M, et al. Recent developments in the field of transparent conductive oxide films for spectral selective coatings, electronics and photovoltaics. Current Applied Physics. 2012;12(Suppl 4):S2-S11.

4. Minami T, Miyata T. Present status and future prospects for development of non- or reduced-indium transparent conducting oxide thin films. Thin Solid Films. 2008;517(4):1474-1477.

5. Liu H, Avrutin V, Izyumskaya N, Özgür Ü, Morkoç H. Transparent conducting oxides for electrode applications in light emitting and absorbing devices. Superlattices and Microstructures. 2010;48(5):458-484. 
6. Kuprenaite S, Murauskas T, Abrutis A, Kubilius V, Saltyte Z, Plausinaitiene V. Properties of In-, Ga-, and Al-doped ZnO films grown by aerosol-assisted MOCVD: Influence of deposition temperature, doping level and annealing. Surface and Coatings Technology. 2015;271:156-164.

7. Huang JM, Ku CS, Lee HY, Lin CM, Chen SY. Growth of high-quality epitaxial $\mathrm{ZnO}$ films on (10-10) sapphire by atomic layer deposition with flow-rate interruption method. Surface and Coatings Technology. 2013;231:323-327.

8. Tanaka H, Ihara K, Miyata T, Sato H, Minami T. Low resistivity polycrystalline $\mathrm{ZnO}$ :Al thin films prepared by pulsed laser deposition. Journal of Vacuum Science \& Technology A. 2004;22(4):1757-1762.

9. Arun Kumar KD, Valanarasu S, Ganesh V, Shkir M, AlFaify S, Algarni $\mathrm{H}$. Effect of potential voltages on key functional properties of transparent AZO thin films prepared by electrochemical deposition method for optoelectronic applications. Journal of Materials Research. 2018;33(11):1523-1533.

10. G-Berasategui E, Zubizarreta C, Bayón R, Barriga J, Barros R, Martins R, et al. Study of the optical, electrical and corrosion resistance properties of AZO layers deposited by DC pulsed magnetron sputtering. Surface and Coatings Technology. 2015;271:141-147.

11. Chang JC, Guo JW, Hsieh TP, Yang MR, Chiou DW, Cheng HT, et al. Effects of substrate temperature on the properties of transparent conducting AZO thin films and CIGS solar cells. Surface and Coatings Technology. 2013;231:573-577.

12. Mickan M, Helmersson U, Rinnert H, Ghanbaja J, Muller D, Horwat D. Room temperature deposition of homogeneous, highly transparent and conductive Al-doped $\mathrm{ZnO}$ films by reactive high power impulse magnetron sputtering. Solar Energy Materials and Solar Cells. 2016;157:742-749.

13. Wang Y, Lu J, Bie X, Gong L, Li X, Song D, et al. Transparent conductive $\mathrm{Al}$-doped $\mathrm{ZnO}$ thin films grown at room temperature. Journal of Vacuum Science \& Technology A. 2011;29(3):031505.

14. Kim DK, Kim HB. Room temperature deposition of Al-doped $\mathrm{ZnO}$ thin films on glass by RF magnetron sputtering under different Ar gas pressure. Journal of Alloys and Compounds. 2011;509(2):421-425.

15. Li W, Hao H, He M, Xing J, Gao H, Dong J. ZnO:Al/Al back reflector with good adhesion on a flexible polyimide substrate for thin film silicon solar cells. Surface and Coatings Technology. 2014;258:991-995.

16. Mickan M, Helmersson U, Horwat D. Effect of substrate temperature on the deposition of Al-doped $\mathrm{ZnO}$ thin films using high power impulse magnetron sputtering. Surface and Coatings Technology. 2018;347:245-251.

17. Zhang Z, Bao C, Yao W, Ma S, Zhang L, Hou S. Influence of deposition temperature on the crystallinity of Al-doped $\mathrm{ZnO}$ thin films at glass substrates prepared by RF magnetron sputtering method. Superlattices and Microstructures. 2011;49(6):644-653.

18. Czternastek $\mathrm{H}$. ZnO thin films prepared by high pressure magnetron sputtering. Opto-Electronics Review. 2004;12(1):4952.
19. Kluth O, Rech B, Houben L, Wieder S, Schöpe G, Beneking C, et al. Texture etched $\mathrm{ZnO}$ : Al coated glass substrates for silicon based thin film solar cells. Thin Solid Films. 1999;351(1-2):247253.

20. Yue H, Wu A, Feng Y, Zhang X, Li T. Structures and properties of the Al-doped $\mathrm{ZnO}$ thin films prepared by radio frequency magnetron sputtering. Thin Solid Films. 2011;519(16):55775581 .

21. Cornelius S, Vinnichenko $\mathrm{M}$. $\mathrm{Al}$ in $\mathrm{ZnO}$ - From doping to alloying: An investigation of Al electrical activation in relation to structure and charge transport limits. Thin Solid Films. 2016;605:20-29.

22. Okuhara Y, Kato T, Matsubara H, Isu N, Takata M. Near-infrared reflection from periodically aluminium-doped zinc oxide thin films. Thin Solid Films. 2011;519(7):2280-2286.

23. Kluth O, Schöpe G, Hüpkes J, Agashe C, Müller J, Rech B. Modified Thornton model for magnetron sputtered zinc oxide: film structure and etching behaviour. Thin Solid Films. 2003;442(1-2):80-85.

24. Hong RJ, Jiang X, Szyszka B, Sittinger V, Xu SH, Werner W, et al. Comparison of the $\mathrm{ZnO}: \mathrm{Al}$ films deposited in static and dynamic modes by reactive mid-frequency magnetron sputtering. Journal of Crystal Growth. 2003;253(1-4):117-128.

25. Choudhary S, Narula R, Gangopadhyay S. Thin Cu film resistivity using four probe techniques: Effect of film thickness and geometrical shapes. AIP Conference Proceedings 2018;1953(1):100054.

26. Vandamme LKJ, Leroy G. Analytical expressions for correction factors for noise measurements with a four-point probe. Fluctuation and Noise Letters. 2006;6(2):L161-178.

27. O'Hanlon JF. A User's Guide to Vacuum Technology. Hobboken: John Wiley \& Sons; 2003.

28. Bortoleto JRR, Chaves M, Rosa AM, da Silva EP, Durrant SF, Trino LD, et al. Growth evolution of self-textured $\mathrm{ZnO}$ films deposited by magnetron sputtering at low temperatures. Applied Surface Science. 2015;334:210-215.

29. Anders A. A structure zone diagram including plasma-based deposition and ion etching. Thin Solid Films. 2010;518(15):40874090 .

30. Rosa AM, da Silva EP, Chaves M, Trino LD, Lisboa-Filho PN, da Silva TF, et al. Structural transition of $\mathrm{ZnO}$ thin films produced by RF magnetron sputtering at low temperatures. Journal of Materials Science: Materials in Electronics. 2013;24(9):31433148 .

31. Kappertz O, Drese R, Wuttig M. Correlation between structure, stress and deposition parameters in direct current sputtered zinc oxide films. Journal of Vacuum Science \& Technology A. 2002;20(6):2084-2095.

32. Zhou HB, Zhang HY, Tan ML, Zhang WJ, Zhang WL. Effects of sputtering pressure on properties of $\mathrm{Al}$ doped $\mathrm{ZnO}$ thin films dynamically deposited by rf magnetron sputtering. Materials Research Innovations. 2012;16(6):390-394.

33. Roth AP, Webb JB, Williams DF. Absorption edge shift in $\mathrm{ZnO}$ thin films at high carrier densities. Solid State Communications. 1981;39(12):1269-1271. 
34. Horwat D, Jullien M, Capon F, Pierson JF, Andersson J, Endrino JL. On the deactivation of the dopant and electronic structure in reactively sputtered transparent Al-doped $\mathrm{ZnO}$ thin films. Journal of Physics D: Applied Physics. 2010;43(13):132003.

35. Yoshioka S, Oba F, Huang R, Tanaka I, Mizoguchi T, Yamamoto T. Atomic structures of supersaturated $\mathrm{ZnO}-\mathrm{Al} 2 \mathrm{O} 3$ solid solutions. Journal of Applied Physics. 2008;103(1):014309.
36. Pan Q, Song X. Al-doped $\mathrm{ZnO}$ films deposited by magnetron sputtering: effect of sputtering parameters on the electrical and optical properties. Materials Science-Poland. 2017;35(2):374381. 